\title{
PAHS Profile of Coal Tars Generated from Coke Production Process and their Toxicity
}

\author{
S Maswanganyi, E Fosso-Kankeu*, N Kumar, R Gusain, F Waanders, J Bunt, Ss Ray, T. Tamane and A. \\ Lombard
}

\begin{abstract}
Coke is the material left when water, coal-gas and coal-tar are driven off during the carbonization of coal at temperatures around $1100{ }^{\circ} \mathrm{C}$ in an air-tight oven, a process refers as cokemaking or coking. Coal tar is produced during the coking process, although often considered for reuse in some other processes, a considerable amount of coal is eventually released in the environment. Coal tars are among the biggest source of Polyclic aromatic hydrocarbons (PAHs) which are carcinogenic and toxic to humans. PAHs are of major concerns as they have the ability to leach into the environment during rain runoffs. In this study, coal tar received from a steel company in South Africa, was characterized using GCXGC-TOFMS to determine the PAHs profile. It was found that the coal tar sample contained more than 100 PAHs among which Naphthalene and Benzo[a]pyrene which exhibited the highest abundance and toxicity equivalent factor (TEF) respectively.
\end{abstract}

\section{Keywords— :Coal Tars, Coking, PAHs, Toxicity}

\section{INTRODUCTION}

South Africa gets about $70 \%$ of its energy from coal [1-14]. The conversion of coal to energy is achieved through combustion of coal. Besides the energy production, coal is also intensively used in steel, oils and coke making [15] .

Industrial processing such as gasification of biomass, coal combustion, coking and pyrolysis can result in tar formation, which is generated as a by-product. Coking is simply an extreme pyrolysis of coal, where coal is heated at temperatures around $1100 \mathrm{oC}$. The process takes place in an oven Battery,

Manuscript received September 30, 2019. This work was supported Water Research Group (WRC) and North West University.

S. Maswanganyi is with the Water Pollution Monitoring and Remediation Initiatives Research Group, School of Chemical and Minerals Engineering, North-West University, Potchefstroom, South Africa.

E. Fosso-Kankeu is with the Water Pollution Monitoring and Remediation Initiatives Research Group, School of Chemical and Minerals Engineering, North-West University, Potchefstroom, South Africa

N Kumar, R Gusain and SS RAY are with DST/CSIR National Centre for Nanostructured Materials, Council for Scientific and Industrial Research, Pretoria 0001, South Africa.

T. Tamane and A. Lombard are with ESKOM Research and Innovation Centre, Rosherville, Johannesburg, South Africa. this battery is composed of many coke ovens stacked in rows and often located at or near an integrated steel mill. In South Africa coking is one of the largest sources of coal tars. It is estimated that around 109000 tonnes of tar was produced in 2013 , this creates an environmental concern as a total of $1.65 \mathrm{~m}$ tonnes of by-products produced in the same period needed space to be disposed with 290 hectares (ha) of land under restoration [16]. Coal tar is a materials driven off as by-product during the production of coke.

Coal tar is defined as the complex and valuable mixtures of Phenols, PAHs and heterocyclic compounds [15]. Coal tars are classified according to their hydrocarbons chains and boiling points. The ones with short rings are referred as phenols and the larger ones are called Poly aromatic hydrocarbons (PAHs) [17]. The transition of tars from lower to higher hydrocarbons is a function of temperature. Tars are considered a threat to the environment when disposed as it is known to be the largest source of Poly aromatic hydrocarbons with the potential of being carcinogenic, mutagenic and toxic[18].

PAHs are important group of compounds of a major environmental concern [19-28]. They are compounds with two or more aromatic hydrocarbons (benzene) rings. PAHs have been reported to be highly carcinogenic and mutagenic in humans hence they are considered an environmental hazard when in contact with water. There are several sources of these aromatic hydrocarbons, some sources can be natural and some are due to anthropogenic activities. Anthropogenic sources are, however, considered the biggest sources of PAHs in the environment [29]. Among the anthropogenic sources, petrogenic and pyrolytic sources are considered to be the most important. PAHs are also called secondary tars as they start forming at a temperature of atleast $800{ }^{\circ} \mathrm{C}$ and decompose at a temperature above $1000^{\circ} \mathrm{C}$. Naphthalene, Phenanthrene, Pyrene and Benzopyrene are examples of PAHs [30]. Due to the fact that PAHs have the potential of being easily transported by rainwater to the nearby water or rivers, polluting the limited water sources [31-44], it is therefore important to assess their toxicity . PAHs that end up in rivers may lead to increased risk for human beings and aquatic life. The interest in this study is only to predict the overall toxicity of the coal tar related to its PAHs content. The 16 EPA (environmental protection agency) priority PAHs will therefore be used as indicators of the toxicity of coal tar since they have been widely studied. According to the literature, $80 \%$ of the total PAHs contribution 
to environmental and health concerns could be attributed to the 16 EPA priority PAHs [45].

In this study PAHs profile was studied using coal tar from ArcelorMittal coking process, Newcastle. Gas chromatography (GC) analytical technique using a Gas Chromatograph X Gas Chromatograph TimeOf-Flight Mass Spectrometry (GCXGC-TOFMS) was used to generate PAHs profile; the toxicity potential of identified PAHs was determined by calculating the toxicity equivalent factors.

\section{EXPERIMENTAL}

Tar samples profile were determined through a two dimensional gas chromatography (GC) analytical technique using a Gas Chromatograph $\mathrm{X}$ Gas Chromatograph Time-Of-Flight Mass Spectrometry (GCXGC-TOFMS) coupled with MS for the relative quantification (area\%) and identification of PAHs. The two-dimensional gas chromatography (GCXGC) utilizes a high frequency modular to divert the entire one-dimensional effluent onto a second-dimensional column. The chromatographic separation space is dramatically increased compared to a conventional 1D-GC analysis, yielding a big leap in potential peak capacity. Samples for GCXGC-TOFMS analysis were prepared by dissolving tar into superior grade hexane (diluting $0.03-1 \mathrm{~mL}$ of sample into $10 \mathrm{~mL}$ volumetric flask). An auto-sampler was utilized for injection and the sample sizes varied from $0.2-1$ $\mu \mathrm{L}$ per injection. The setting of the GCXGC-TOFMS was done according to the basic set-up recommended by the supplier.

\section{RESULTS AND DISCUSSION}

\section{A. PAHs Profile For The Newcastle Tar}

The polyaromatic hydrocarbons (PAHs) have been reported as the major components of coal-derived products and thermally cracked petroleum oils [46]; PAHs are toxic and/or mutagenic in biological systems and must therefore be seriously considered in coal tar. The coal tar PAH composition was determined using GCXGC-TOFMS and the results are shown in Table I. A variety of PAHs were observed in the coal tars from the coking process at Arcelor Mittal South Africa, with a dominance of naphthalene. The toxicities of PAHs have been reported to be related to specific structures and positions of ring substitution [46]. More than 100 PAHs were identified in tars from the coking process, but only the PAHs listed among the 16 priority EPA PAHs will be considered in this study.

Among the PAHs identified, 10 EPA priority PAHs were detected in the tar from the coking process; of these EPA priority PAHs, 4 have been classified as those with the potential to cause cancer to humans. The complete EPA list has 7 carcinogenic PAHs. Cancer causing PAHs are classified as either group 1, 2A or $2 \mathrm{~B}$. The description of the classification numbers is presented in Table II below. Many studies have reported that these 7 PAHs cause lung and skin cancer in humans.
TABle I: NeWCATLE COAL TAR CHARACTERISTICS

\begin{tabular}{|c|c|c|c|c|}
\hline PAHs names & $\begin{array}{l}\text { Number of } \\
\text { rings }\end{array}$ & $\begin{array}{l}\text { IARC } \\
\text { classificatio } \\
\mathrm{n}\end{array}$ & Area & Structure \\
\hline Naphthalene & 2 & $2 \mathrm{~B}$ & 4.84 & linear \\
\hline Acenaphthene & 3 & N/A & 0.14 & clustered \\
\hline Acenaphthylene & 3 & 3 & 0.096 & clustured \\
\hline Fluorene & 3 & 3 & 0.241 & linear \\
\hline Phenanthrene & 3 & 3 & 1.237 & angular \\
\hline Anthracene & 3 & 3 & 0.076 & linear \\
\hline Pyrene & 4 & $2 \mathrm{~A}$ & 2.188 & clustered \\
\hline $\begin{array}{l}\text { Benzo (k) } \\
\text { anthracene }\end{array}$ & 4 & $2 \mathrm{~B}$ & 0.63 & angular \\
\hline $\begin{array}{l}\text { Benzo (k) } \\
\text { fluoranthene }\end{array}$ & 5 & $2 \mathrm{~B}$ & 0.605 & angular \\
\hline Benzo (a) Pyrene & 5 & 1 & 0.176 & clustered \\
\hline
\end{tabular}

TABLE II:CLASSIFICATION OF PAHS

\begin{tabular}{ll}
\hline \hline $\begin{array}{l}\text { IARC } \\
\text { classification }\end{array}$ & Definition \\
\hline Group 1 & Carninogenic to humans \\
Group 2A & Probably carcinogenic \\
Group 2B & Possibly carcimenic \\
Group 3 & Not classifiable \\
\hline \hline
\end{tabular}

PAHs have also been classified by IARC and DHHS as carcinogenic in animals in which they cause bladder, liver and stomach cancer [47]. The coking tar contains Benzo (a) pyrene which has been identified as the environmental indicator of PAHs [48]. Therefore, the NewCastle coking tar has the potential of threatening the health of humans and animals when it gets in contact with them either by direct handling of tar or through exposure to contaminated surface water or groundwater. Although the coal tar analysis did not give the exact concentration level of the PAHs in the tar, the areas under a peak which is proportional to the concentration of PAHs in coal tars could be obtained (Fig. 1).

The size of the area therefore reflects the abundance of the PAHs in the tar; PAHs with high areas are the more abundant. Different concentration level of the PAHs may depend on the type of tar production process, coal rank, operating conditions and other factors. The abundance of PAH is well presented by the bar graph in Fig. 1. It can be seen that Naphthalene has the highest area for both tars and therefore is the most abundant PAH. More PAHs with higher concentrations may be found in the tar produced at temperatures lower than $1200{ }^{\circ} \mathrm{C}$ because the formation of PAHs mixtures is a function of temperature [15]. The decomposition of PAHs is likely to take place at temperatures higher than $1000{ }^{\circ} \mathrm{C}$. 


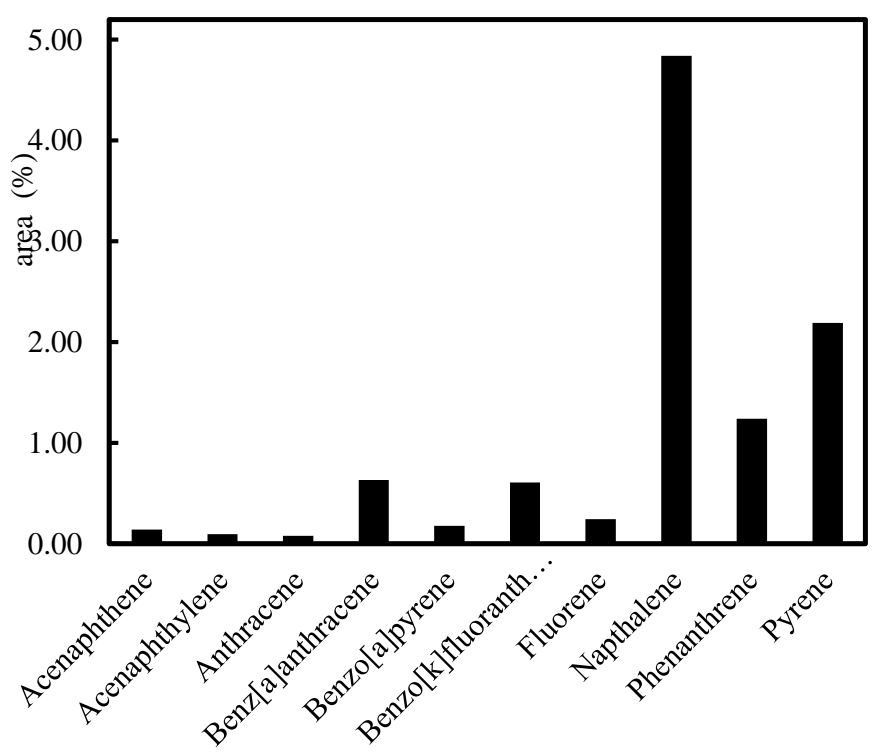

Fig. 1. Abundance of PAHs in coal tar

\section{B. Toxicity Of Pahs And Risk Of Exposure}

PAHs can be carcinogenic, genotoxic, mutagenic and teratogenic. However, not all toxic PAHs are carcinogenic [47] The toxicity of the 7 PAHs identified by the EPA as carcinogens is not of the same extent. Benz[a]anthracene, Benzo[a]pyrene, Naphthalene and Benzo[k]fluoranthene are the carcinogens that have been identified in this study. However, not all of them have the same carcinogenic potency. The carcinogenic or toxicity potency of the PAHs is associated with the structural features and the complexity of the molecule [49]. A more complex compound is usually the more potent [49]. The number of benzene rings or the molecular weight of PAHs is one of the examples of structural features that can affect the carcinogenic potency. PAHs have benzene rings bonded in linear, angular or clustered arrangement [17]. The difference in the arrangement of the rings results in PAHs having different carcinogenic effects.

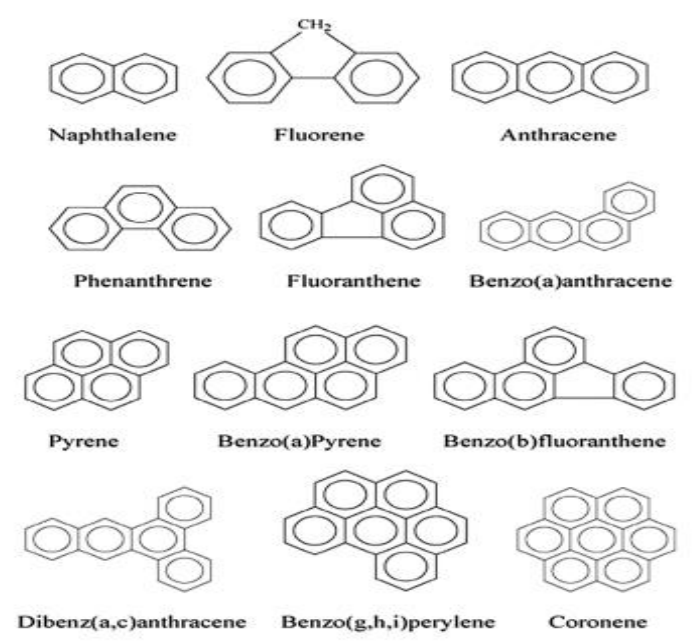

Fig.2 Chemical strustures of some of the common PAHs
Fig. 2 shows the chemical structures of some of the most studied PAHs. PAHs with clustered or angular arrangements have higher carcinogenic potency than linear PAHs [17]. Also, larger PAHs (more than 6 rings) are more potent than smaller PAHs (2-5 rings) [17]. Benz[a]anthracene is more toxic than Naphthalene because it has a more complex structure and more number of rings than Naphthalene. Although Benzo[k]fluoranthene and Benzo[a]pyrene have the same number of rings, their ring arrangement is different. Benzo[a]pyrene has a more complex structure than Benzo[k]fluoranthene, hence it is more toxic. Out of all the PAHs found in both coal tars, Naphthalene is a less toxic PAH because it has the lowest number of rings (i.e. two rings) and it possesses a linear arrangement.

In contrast, Benzo[a]pyrene has 5 rings with clustered arrangement; therefore, it is the most toxic. However, Benzo[a]pyrene cannot be the only PAH considered when looking at the dangers related to the exposure to coal tars. The risks related to exposure to PAHs could never be related to single PAHs but to mixtures of them. The toxicity of PAHs is higher for mixtures than for single PAHs and the health effects of individual PAHs are not the same as the health effects of PAHs mixtures [17]. Therefore, understanding the mixtures of PAHs instead of single PAHs gives an accurate assessment of the dangers of the PAHs. Nontoxic PAHs may still show adverse effects on humans and animals when they appear in mixtures due to different factors such as the mechanism of metabolism, age and pre-existing health effects [47]. Owing to the fact that PAHs require activation of electrophilic metabolites to exert their carcinogenic effects, in other words PAHs must be metabolised to their diol epoxide or metabolites [17].

In mixtures, weaker or smaller PAHs may increase the rate of metabolism which will increase the toxicity effect. According to occupational studies on workers exposed to PAHs, it was found that mixtures of PAHs are carcinogenic to humans [45]. Therefore, Acenaphthene, Acenaphthylene, Anthracene, Fluorene, Phenanthrene, and Pyrene cannot be overlooked, because exposure to mixtures containing these PAHs may also cause adverse health effects. These non-carcinogenic PAHs have reactive metabolites such as epoxides and dihydroidiols that can bind to cellular proteins and DNA [47]. The resulting biochemical disruptions and cell damage lead to mutations and development of malformations and tumors [47]

\section{Toxic Equivalency Factors}

The International Agency for Research on Cancer (IARC) classification criteria does not indicate more potent and less potent PAHs [48]. To conduct a reasonable risk assessments, the potency of individual PAHs have to be known and this is determined by assigning Toxic equivalency factors (TEFs) [48]. Only limited number of PAHs has been extensively studied for provision of toxicity criteria. The risks posed by PAHs mixtures has been investigated by EPA, making an assumption that all carcinogenic PAHs are as potent as Benzo[a]pyrene $(\mathrm{Ba}[\mathrm{a}] \mathrm{P})$, one of the most potent PAHs [50]. The available 
information that has been collected recently suggests that most are considerably less potent than $\mathrm{Ba}$ [a] $\mathrm{P}$ and therefore, the EPA approach is likely to overestimate risks [48]. The basis of risk assessment considered by the EPA consisted to split the PAHs into two subclasses of carcinogenic $(\mathrm{TEF}=1)$ and non-carcinogenic (TEF=0) PAHs [51]. A new TEF approach by Nisbet and LaGoy (1992) has been adopted to yield a set of TEFs which will assist in accurately predicting risks associated to the different PAHs based on the current knowledge [48]. The approach assigns TEFs to individual PAHs based on the data from previous studies and elevated tumor incidences [48]. Furthermore, this approach assigns TEFs to PAHs determined to be not carcinogenic by IARC or EPA. PAHs are assigned 1, $0.1,0.01$ or 0.001 [51]. A TEF of 1 is assigned to PAHs with high cancer potency, 0.1 to carcinogenic PAHs with low potency, 0.01 to PAHs with limited carcinogenic potency and finally 0.001 to PAHs with little if any cancer potency.

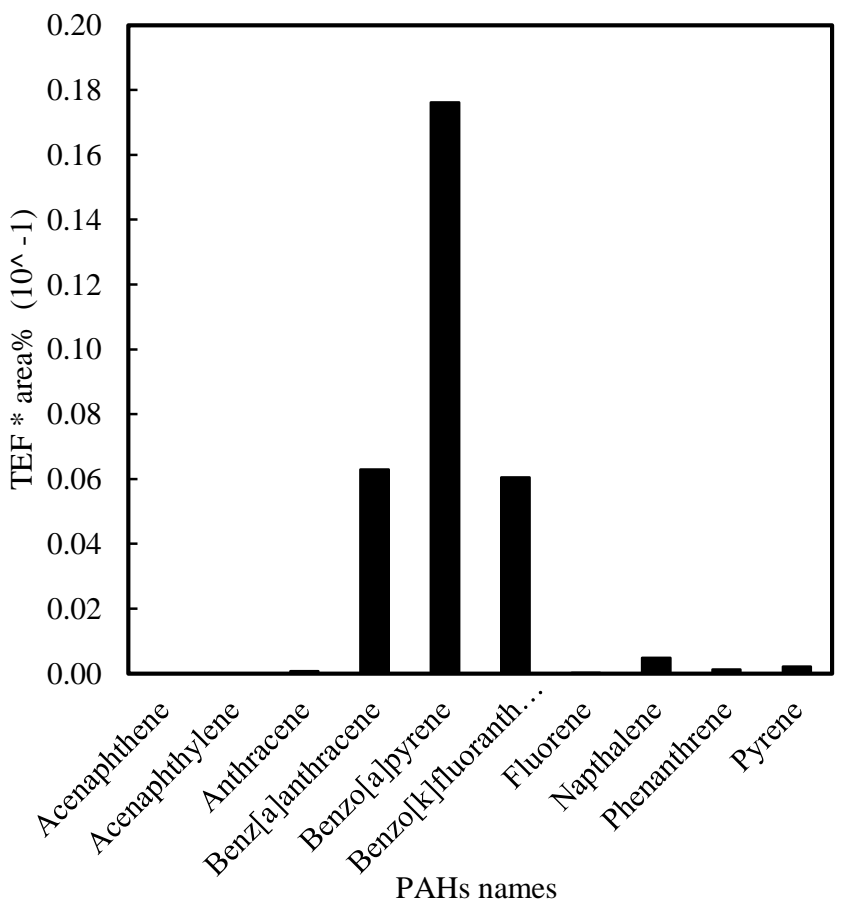

Fig. 3. Aproximate TEQs of individual PAHs in coal tar

For the evaluation of the toxicity of known PAHs, toxic equivalents (TEQ) are calculated as the product of the individual PAH concentration and its corresponding TEF [52]. In this case the toxicity was estimated using an area which is proportional to the concentration. Fig. 3 shows the toxic potential of individual PAHs. It is evident from the graph that Benzo[a]pyrene is the most toxic, followed by Benzo[a]anthracene. From this graph it can be concluded that although the Benzo[a]pyrene content in the coal tar is relatively low, the estimated toxicity may be of serious concern. On the other hand, all other PAHs can exhibit high toxicity if their content in the coal tar is increased.
TABLE III: TOXIC EQUIVALENT FACTORS OF PAHS

\begin{tabular}{lll}
\hline \hline & \multicolumn{2}{l}{ Toxic Equivalent factors(TEQ) } \\
\hline PAH compound & EPA & Nisbtet and LaGoy \\
\hline Dibenz & 1 & 1 \\
(a,h)anthracene & & 1 \\
Benzo(a)pyrene & 1 & 0.1 \\
Benzo(a)anthracene & 1 & 0.1 \\
Benzo(b)fluoranthene & 1 & 0.1 \\
Benzo(k)fluoranthene & 1 & 0.1 \\
Indeno(123-cd)pyrene & 1 & 0.01 \\
Anthracene & 0 & 0.01 \\
Benzo(g,h,i)perylene & 0 & 0.01 \\
Chrysene & 1 & 0.001 \\
Acenaphthene & 1 & 0.001 \\
Acenaphthylene & 0 & 0.001 \\
Fluoranthene & 0 & 0.001 \\
Fluorene & 0 & 0.001 \\
2-methylnaphthalene & 0 & 0.001 \\
Naphthalene & 0 & 0.001 \\
Phenanthrene & 0 & 0.001 \\
Pyrene & 0 & \\
\hline \hline
\end{tabular}

\section{Toxicity Of Non-EPA PAHs}

There are some toxic PAHs not included in the EPA list. As mentioned above the determination of the exact health effects of a given PAH during epidemiological studies will be quite challenging since most exposures are to PAH mixtures. Recent studies have discovered that 7, 12-dimethylbenzo anthracene (DMBA) which is a non-EPA PAH, has the potential of increasing the risk of breast cancer in animals through a variety of mechanisms [47]. DMBA tends to accumulate and persists in the adipose tissue of the mammary gland due to the fact that it is a fat soluble compound, this eventually contributes to increase the exposure of mammary epithelium to this chemical carcinogen [47]. This PAH has shown its carcinogenicity effects on experimental rats and it is an indirect carcinogen, requiring metabolic activation to yield its ultimate carcinogenic forms [47].

\section{CONCLUSION AND RECOMMENDATIONS}

The PAHs profile of coal tars from the coking process at Arcelor Mittal was determined using Gas Chromatography and showed that Newcastle tar contained a host of different PAHs, but the focus was mainly placed on those classified by the United States Environmental Protection Agency (US-EPA) as priority pollutants. Among the selected PAHs, naphthalene was found to be the most abundant in both tars, however, based on the toxic equivalent factor which gives an indication of the potency of individual PAHs, Benzo[a]pyrene was the most toxic PAH, followed by Benzo[a]anthracene and Benz[k]fluoranthene which all occurred in the tar from the coking process. These PAHs have been reported to be related to elevated tumor incidences and therefore have high cancer potency. However, it is also important to note that the mixture 
of less potent PAHs increases their toxicity effects toward humans. Therefore, the discharge of all these coal tars in the environment is likely to pause significant risks to the ecosystems once the PAHs are naturally leached into surface and groundwater and dispersed to the water network. It is therefore important to carry out further study to understand the susceptibility of PAHs release from coal tar and develop suitable photocatalytic methods for their degradation in aqueous solutions.

\section{ACKNOWLEDGEMENTS}

The authors are thankful to the sponsors: the Water Research Commission (WRC, Project 2974) and the North-West University in South Africa. The authors are also grateful to Eskom, South Africa for providing facilities for the characterisation of materials. The author also acknowledge the laboratory assistance of Mr N Lemmer.

\section{REFERENCES}

[1] T. C. Khethane, E. Fosso-Kankeu, F. Waanders, and J. Bunt, "PAHs Content of Tar Produced from Fischer Assay of Medium Rank C Bituminous South African Coal," Science, Engineering, Technology \& Waste Management, pp. 27-28, 2017.

[2] Elvis Fosso-Kankeu. 2019. Nano and Bio-based Technologies for wastewater treatment: Prediction and Control Tools for the dispersion of Pollutants in the Environment. Wiley Scrivener. ISBN: 978-1-119-57709-6. Pp 301-336.

[3] Elvis Fosso-Kankeu. 2019. New Horizons in Wastewaters Management: Emerging Monitoring and Remediation Strategies. Nova Science Publishers. ISBN: 978-1-53615-659-1.

[4] J.G. Redelinghuys, E. Fosso-Kankeu, G. Gericke, F. Waanders. 2019. Coal Power Plant Wastewater Treatment by Thermal and Membrane Technologies. In Nano and Bio-based Technologies for wastewater treatment: Prediction and Control Tools for the dispersion of Pollutants in the Environment. Editor: Elvis Fosso-Kankeu. Wiley Scrivener. ISBN: 978-1-119-57709-6. Pp 149-168. https://doi.org/10.1002/9781119577119.ch5

[5] N. Mukwevho, E. Fosso-Kankeu, F. Waanders. 2019. PAHs Released from Coal Tars and Potential Removal Using Nanocatalysts. In Nano and Bio-based Technologies for wastewater treatment: Prediction and Control Tools for the dispersion of Pollutants in the Environment. Editor: Elvis Fosso-Kankeu. Wiley Scrivener. ISBN: 978-1-119-57709-6. Pp 169-203. https://doi.org/10.1002/9781119577119.ch6

[6] Johannes Cornelius van der Linde, Elvis Fosso-Kankeu, Gerhard Gericke, Frans Waanders, Louise Dreyer, Nico Lemmer. 2019. Flocculant types and operating conditions influencing particles settling rates in feed water used at a coal power plant. Desalination and Water Treatment. 150: 293-300. https://doi.org/10.5004/dwt.2019.23735

[7] E. Fosso-Kankeu, A.F. Mulaba-Bafubiandi, T. Strydom, Bioprocessing of South African coal and its impact on coal mineral content. International Conference on Chemical, Industrial, Environmental, Mining and Metallurgical Engineering (ICCIEMME 2013); and International Conference on Energy, Nanotechnology and Environmental Sciences (ICENES 2013). April 15-16, 2013 Johannesburg (South Africa). Editors: Sandhu S and Muzenda E. ISBN: 978-93-82242-26-0. 2013.

[8] E. Fosso-Kankeu, M. Mohuba, A.F. Mulaba-Bafubiandi, Development of hydro-thermal demineralization technique for cost effective quality upgrading of South African coal. 27-28 November 2013, Johannesburg-South Africa. ISBN: 978-93-82242-50-5. 2013.

[9] N. Mukwevho, E. Fosso-Kankeu, F. Waanders, G. Gericke, J. Bunt, Synthesis and characterization of $\mathrm{ZnO}$ nanoparticle and application in the photodegradation of organic pollutants in effluents from coal power station. International Conference on Advances in Science, Engineering, Technology and Natural Resources (ICASETNR-16) Nov. 24-25, 2016, Parys - South Africa. ISBN: 978-93-84468-79-8. 2016.
[10] E. Fosso-Kankeu, F. Waanders, R. Swiegers, I.O. Ntwampe, D. Rogers, G. Gericke, Impact of the physico-chemical properties of water on the flocculation performance of lime, clay and other polymers. International Conference on Advances in Science, Engineering, Technology and Natural Resources (ICASETNR-16) Nov. 24-25, 2016, Parys - South Africa. ISBN: 978-93-84468-79-8. 2016.

[11] E. Fosso-Kankeu, F.B. Waanders, G. Gericke, N. Lemmer, L.M. Dreyer and J. van der Linde, Investigation of the potential of monomeric and polymeric coagulants in the treatment of raw water used at a coal-fired power station. $9^{\text {th }}$ Int'l Conference on Advances in Science, Engineering, Technology \& Waste Management (ASETWM-17). 27-28 November 2017, Parys, South Africa. Editors: F. Waanders, E. Fosso-Kankeu, B. Topcuoglu, M. Plaisent, Y. Thaweesak. ISBN: 978-81-934174-6-1. Pp. 44-48. 2017.

[12] E. Fosso-Kankeu, C.E. Brider, J. Redelinghuys, G. Gericke, N. Lemmer, F. Waanders, Determination of suitable anti-scaling agent to inhibit scale formation of water processed in coal power plant system. $9^{\text {th }}$ Int'l Conference on Advances in Science, Engineering, Technology \& Waste Management (ASETWM-17). 27-28 November 2017, Parys, South Africa. Editors: F. Waanders, E. Fosso-Kankeu, B. Topcuoglu, M. Plaisent, Y. Thaweesak. ISBN: 978-81-934174-6-1. Pp. 30-36. 2017.

[13] JC van der Linde, E Fosso-Kankeu, G Gericke, F Waanders and T. Tamane. 2018. Effect of Temperature on the Performance of Rheofloc: Conductivity Removal from RO-reject. Editors: Elvis Fosso-Kankeu, Frans Waansders, Michel Plaisent. 10th Int'l Conference on Advances in Science, Engineering, Technology \& Healthcare (ASETH-18) Nov. 19-20, 2018 Cape Town (South Africa). ISBN: 978-81-938365-2-1. Vol II. Pp 139-143.

[14] E. Fosso-Kankeu, L. Van Schalkwyk, J. Van Der Linde, G. Gericke and F.B. Waanders. 2018. Pretreatment of Coal Power Plant RO Retentate using AR Floc 100. Editors: Elvis Fosso-Kankeu, Frans Waansders, Michel Plaisent. 10th Int'l Conference on Advances in Science, Engineering, Technology \& Healthcare (ASETH-18) Nov. 19-20, 2018 Cape Town (South Africa). ISBN: 978-81-938365-2-1. Vol II. Pp 149-154.

[15] L. et al. Jin, "Effect of temperature and simulated coal gas composition on tar production during pyrolysis of a subbituminous coal Fuel,' pp. 11291137, 2019.

https://doi.org/10.1016/j.fuel.2018.12.093

[16] Arcelormittal south Africa, Parliament colloquium on beneficiation, 24 August 2014. Available: https://www.thedti.gov.za/parliament/2014/ArcelorMittal.pdf

[17] H. I. Abdel-Shafy, and M.S.M. Mansour," A review on polycyclic aromatic hydrocarbons: Source, environmental impact, effect on human health and remediation" Egyptian Journal of Petroleum, 25(1). pp.107-123. https://doi.org/10.1016/j.ejpe.2015.03.011

[18] E. Mulder, J. P Brouwer, J. Blaakmeer, and J. W. FreÂnay, "Immobilisation of PAH in waste materials," Waste Management, pp. 247-253, 2001 https://doi.org/10.1016/S0956-053X(00)00097-0

[19] H. Gupta, and B. Gupta, "Photocatalytic degradation of polycyclic aromatic hydrocarbon benzo[a]pyrene by iron oxides and identification of degradation products," elsevier Chemosphere, pp. 924-931, 2015. https://doi.org/10.1016/j.chemosphere.2014.12.028

[20] Sadanand Pandey, Gopal Krishna Goswami, Hussein Kehinde Okoro, Elvis Fosso-Kankeu. 2019.Carbon nanotubes in the 21st Century: An Advancement in real time monitoring and control of environmental water. In Nano and Bio-based Technologies for wastewater treatment: Prediction and Control Tools for the dispersion of Pollutants in the Environment. Editor: Elvis Fosso-Kankeu. Wiley Scrivener. ISBN: 978-1-119-57709-6. Pp 263-300.

[21] N Mukwevho, N Kumar, E Fosso-Kankeu, F Waanders, J Bunt, SS Ray. 2019. Visible light-excitable $\mathrm{ZnO} / 2 \mathrm{D}$ graphitic-C3N4 heterostructure for the photodegradation of naphthalene. Desalination and Water Treatment. 163: 286-296 https://doi.org/10.5004/dwt.2019.24422.

[22] Nthambeleni Mukwevho, Rashi Gusain, Elvis Fosso-Kankeu, Neeraj Kumar, Frans Waanders, Suprakas Sinha Ray. 2019. Removal of naphthalene from simulated wastewater through adsorption-photodegradation by $\mathrm{ZnO} / \mathrm{Ag} / \mathrm{GO}$ nanocomposite. Journal of Industrial and Engineering Chemistry. https://doi.org/10.1016/j.jiec.2019.09.030

[23] N Mukwevho, E Fosso-Kankeu, N Kumar, R Gusain, S Ray, F Waanders. 2019. PAHs in coal tar as water contaminants and their removal by 
photocatalytic degradation. IMWA 2019 Conference "Mine Water Technological and Ecological Challenges". 15-19 July 2019, Perm, Russia. Elena Khayrulina and Christian Wolkersdorfer. ISBN: 978-5-91252-145-4. Pp 179-183.

[24] N. Mukwevho, E. Fosso-Kankeu, F. Waanders, N. Kumar, S.S. Ray, X.Y Mbianda, Evaluation of the photocatalytic activity of $\mathrm{Gd}_{2} \mathrm{O}_{2} \mathrm{CO}_{3} . \mathrm{ZnO}$.CuO nanocomposite used for the degradation of phenanthrene. Springer Nature Applied Sciences. 2018. https://doi.org/10.1007/s42452-018-0012-0

[25] N. Mukwevho, E. Fosso-Kankeu, F. Waanders, N. Kumar, S.S. Ray, Synthesis and properties of $\mathrm{ZnO} / \mathrm{Ag} /$ graphene oxide composites photocatalyst. $9^{\text {th }}$ Int'l Conference on Advances in Science, Engineering, Technology \& Waste Management (ASETWM-17). 27-28 November 2017, Parys, South Africa. Editors: F. Waanders, E. Fosso-Kankeu, B. Topcuoglu, M. Plaisent, Y. Thaweesak. ISBN: 978-81-934174-6-1. Pp. 49-52. 2017

[26] Nthambeleni Mukwevho, Elvis Fosso-Kankeu, Frans Waanders, John Bunt, Dewald de Bruyn, Neeraj Kumar and Suprakas Sinha Ray. 2018. Sol-gel preparation of $\mathrm{ZnO} / \mathrm{SnO} 2$ composite photocatalysts applied for the degradation of PAH's under visible light. Editors: Elvis Fosso-Kankeu, Frans Waansders, Michel Plaisent. 10th Int'l Conference on Advances in Science, Engineering, Technology \& Healthcare (ASETH-18) Nov. 19-20, 2018 Cape Town (South Africa). ISBN: 978-81-938365-2-1. Vol II. Pp 173-177.

[27] Elvis Fosso-Kankeu, Dewald de Bruyn, Nthambeleni Mukwevho and Frans Waanders. 2018. Photocatalytic Degradation of Naphthalene Using Tin Dioxide Nanomaterial under Visible Light. Editors: Elvis Fosso-Kankeu, Frans Waansders, Michel Plaisent. 10th Int'l Conference on Advances in Science, Engineering, Technology \& Healthcare (ASETH-18) Nov. 19-20, 2018 Cape Town (South Africa). ISBN: 978-81-938365-2-1. Vol I. Pp 79-83.

[28] N. Mukwevho, E. Fosso-Kankeu, F. Waanders, G. Gericke, J. Bunt, Synthesis and characterization of $\mathrm{ZnO}$ nanoparticle and application in the photodegradation of organic pollutants in effluents from coal power station. International Conference on Advances in Science, Engineering, Technology and Natural Resources (ICASETNR-16) Nov. 24-25, 2016, Parys - South Africa. ISBN: 978-93-84468-79-8. 2016.

[29] J Bergendahl, Batch Leaching Tests: Colloid Release and PAH Leachability. Soil \& Sediment Contamination, pp. 527-543,2007. https://doi.org/10.1080/15320380500263725

[30] L. Roetsa, J. R Bunta, H. . W. Neomagusa, and D. van Niekerkb, "An evaluation of a new automated duplicate-sample Fischer Assay setup according to ISO/ASTM standards and analysis of the tar fraction," Journal of Analytical and Applied Pyrolysis, pp. 190-196, 2014. https://doi.org/10.1016/j.jaap.2014.01.016

[31] E Fosso-Kankeu, R Weideman, D Moyakhe, FB Waanders, M Le Roux, QP Campbell. 2019. Hydrothermal preparation of biochar from spent coffee grounds, and its application for the removal of cadmium from coal tailings leachate. The Journal of the Southern African Institute of Mining and Metallurgy. 119: 607-612. https://doi.org/10.17159/2411-9717/449/2019

[32] E. Fosso-Kankeu, P. Jagals, H. Du Preez, Exposure of rural households to toxic cyanobacteria in container-stored water. Water SA, Vol. 34, no. 5, pp. 631-636, 2008. https://doi.org/10.4314/wsa.v34i5.180660

[33] E. Fosso-Kankeu, A. Mulaba-Bafubiandi, B.B. Mamba, T.G. Barnard, Mitigation of $\mathrm{Ca}, \mathrm{Fe}$, and $\mathrm{Mg}$ loads in surface waters around mining areas using indigenous microorganism strains. Journal of Physics and Chemistry of the Earth, Vol. 34, pp. 825-829, 2009. https://doi.org/10.1016/j.pce.2009.07.005

[34] E. Fosso-Kankeu, H. Du Preez, P. Jagals, The health implication of relationships between bacterial endotoxin, cyanobacteria, coliforms and water stored in domestic containers of rural households in South Africa. Journal of Water and Health, Vol. 8, no. 4, pp. 601-610, 2010. https://doi.org/10.2166/wh.2010.094

[35] E. Fosso-Kankeu, A. Mulaba-Bafubiandi, B.B. Mamba, L. Marjanovic, T.G. Barnard, A comprehensive study of physical and physiological parameters that affect biosorption of metal pollutants from aqueous solutions. Journal of Physics and Chemistry of the Earth, Vol. 35, pp. 672-678, 2010 https://doi.org/10.1016/j.pce.2010.07.008

[36] E. Fosso-Kankeu, A.F. Mulaba-Bafubiandi, B.B. Mamba and T.G Barnard, Prediction of metal-adsorption behaviour in the remediation of water contamination using indigenous microorganisms. Journal of Environmental Management. Vol. 92, no. 10, pp. 2786-2793, 2011 https://doi.org/10.1016/j.jenvman.2011.06.025

[37] H. Mittal, E. Fosso-Kankeu, Shivani B. Mishra, Ajay K. Mishra, Biosorption potential of Gum ghatti-g-poly (acrylic acid) and susceptibility to biodegradation by B. subtilis. International Journal of Biological Macromolecules. Vol. 62, pp. 370-378, 2013. https://doi.org/10.1016/j.ijbiomac.2013.09.023

[38] E. Fosso-Kankeu, H. Mittal, S.B. Mishra, A.K. Mishra, Gum ghatti and acrylic acid based biodegradable hydrogels for the effective adsorption of cationic dyes. Journal of Industrial and Engineering Chemistry. Vol. 22, pp. 171-178, 2015. https://doi.org/10.1016/j.jiec.2014.07.007

[39] E. Fosso-Kankeu, H. Mittal, F. Waanders, I.O. Ntwampe, S.S. Ray, Preparation and characterization of gum karaya hydrogel nanocomposite flocculant for metal ions removal from mine effluents. International Journal of Environmental Science and Technology. Vol. 13, pp. 711-724, 2016. https://doi.org/10.1007/s13762-015-0915-x

[40] E. Fosso-Kankeu, F. Waanders, E. Maloy, Copolymerization of ethyl acrylate onto guar gum for the adsorption of $\mathrm{Mg}$ (II) and $\mathrm{Ca}$ (II) ions. Desalination and Water Treatment. doi: 10.1080/19443994.2016.1165147: pp. 1-10, 2016.

[41] E. Fosso-Kankeu, F. Waanders, C.L. Fourie, Adsorption of Congo Red by surfactant-impregnated bentonite clay. Desalination and Water Treatment. doi: 10.1080/19443994.2016.1177599: pp. 1-9, 2016.

[42] E. Fosso-Kankeu, A. Manyatshe, F. Waanders, Mobility potential of metals in acid mine drainage occurring in the Highveld area of Mpumalanga Province in South Africa: Implication of sediments and efflorescent crusts. International Biodeterioration and Biodegradation. Vol. 119, pp. 661-670, 2017. https://doi.org/10.1016/j.ibiod.2016.09.018

[43] E. Fosso-Kankeu, H. Mittal, F. Waanders, S.S. Ray, Thermodynamic properties and adsorption behaviour of hydrogel nanocomposites for cadmium removal from mine effluents. Journal of Industrial and Engineering Chemistry. Vol. 48, pp. 151-161, 2017. https://doi.org/10.1016/j.jiec.2016.12.033

[44] E. Fosso-Kankeu, 2018. Synthesized af-PFCl and GG-g-P(AN)/TEOS hydrogel composite used in hybridized technique applied for AMD treatment. Journal of Physics and Chemistry of the Earth. 2018. https://doi.org/10.1016/j.pce.2018.02.015

[45] A. Adeniji, O. Oluranti Okoh, and A. Ifeanyi Okoh, "Analytical Methods for Polycyclic Aromatic Hydrocarbons and their Global Trend of Distribution in Water and Sediment: A Review," 2018a. https://doi.org/10.5772/intechopen.71163

[46] M. Nishioka, R. M Campbell, M. L. Lee and R. N. Castle, "Isolation of sulphur heterocycles from petroleum and coal-derived materials by ligand exchange chromatography," Fuel 65. pp. 270-273, 1986b. https://doi.org/10.1016/0016-2361(86)90019-0

[47] T. Rengarajan, P. Rajendran, N. Nandakumar, B. Lokeshkumar, P. Rajendran, and I. Nishigaki, "Exposure to polycyclic aromatic hydrocarbons with special focus on cancer," Asian Pacific Journal of Tropical Biomedicine, 5(3). Pp. 182-189, 2015. https://doi.org/10.1016/S2221-1691(15)30003-4

[48] I.C.T. Nisbet, and P.K. LaGoy, "Toxic equivalency factors (TEFs) for polycyclic aromatic hydrocarbons (PAHs)," Regulatory Toxicology and Pharmacology, 16(3). pp. 290-300, 1992. https://doi.org/10.1016/0273-2300(92)90009-X

[49] Y. Guo, Y., K.S. Wu,., X. Huo, and X. Xu, "Sources, Distribution, and Toxicity of Polycyclic Aromatic Hydrocarbons," Journal of environmental health, 7. pp. 22-25, 2011.

[50] S. Richter-Brockmann, and C. Achten, "Analysis and toxicity of $59 \mathrm{PAH}$ in petrogenic and pyrogenic environmental samples including dibenzopyrenes, 7H-benzo[c]fluorene, 5-methylchrysene and 1-methylpyrene," Chemosphere, 200. pp. 495-503, 2018. https://doi.org/10.1016/j.chemosphere.2018.02.146

[51] G. C. Fang, K. F. Chang, C. Lu, and H. Bai, "Toxic equivalency factors study of polycyclic aromatic hydrocarbons (PAHs)" in Taichung City, Taiwan., Toxicology and Industrial Health, 18 (6). Pp. 279-288. 2002. https://doi.org/10.1191/0748233702th151oa

[52] R Meng, Y. Liu, X. Lu, S. Zhang, T. Jin, B. Wang, Q. Tang, Z. Liu, Y. Guo, X. Zhou, and B. Xi, "A review on occurrence and risk of polycyclic aromatic hydrocarbons (PAHs)," in lakes of China. Science of The Total Environment, 651. pp. 2497-2506, 2019. https://doi.org/10.1016/j.scitotenv.2018.10.162 


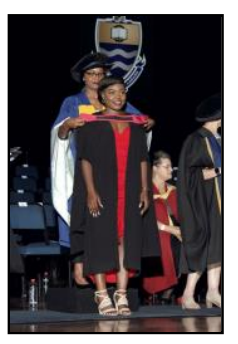

S. Maswanganyi is currently pursuing her Master's degree in chemical engineering at Northwest

University. She completed her undergraduate degree a Bsc degree in chemical engineering from University of Witwatersrand, Johannesburg in 2018. 